\title{
Fear of falling and physical performance among older Czech adults
}

\author{
PETRA KURKOVÁ ${ }^{1, A, c-F}$, HELENA KISVETROVÁ ${ }^{2, A, ~ c-G}$, MICHAELA HORVÁTHOVÁ ${ }^{1, \text { B }}$ \\ ORCID ID: 0000-0003-0856-8074 \\ JITKA TOMANOVÁ2, в, D-F, MILENA BRETŠNAJDROVÁ ${ }^{3, \text { в, D-F, ROMAN HERZIG }}$, B, D-F
}
${ }^{1}$ Department of Anthropology and Health Education, Faculty of Education, Palacký University Olomouc, Olomouc, Czech Republic
${ }^{2}$ Centre for Research and Science, Faculty of Health Sciences, Palacký University Olomouc, Olomouc, Czech Republic ${ }^{3}$ II. Internal Clinic of Gastroenterology and Geriatrics, University Hospital Olomouc, Olomouc, Czech Republic ${ }^{4}$ Neurology Clinic, University Hospital Hradec Králové, Hradec Králové, Czech Republic

A - Study Design, B - Data Collection, C - Statistical Analysis, D - Data Interpretation, E - Manuscript Preparation, F - Literature Search, G - Funds Collection

Summary Background. The fear of falling (FoF) refers to a lack of self-confidence that normal activities can be performed without falling. FoF represents an important psychological factor at an older age.

Objectives. This study aimed to analyse the factors associated with FoF in a sample of community-dwelling older Czech adults. Material and methods. A cross-sectional study was performed in 2017-2018. The Falls Efficacy Scale-International and the Short Physical Performance Battery were completed by 349 older adults with $(n=140)$ and without $(n=209)$ dementia. Fisher's exact test, analysis of variance and logistic regression models were used for statistical analyses.

Results. Cognitive impairment, age and physical frailty were significantly associated with higher FoF. In three models of linear regression, associations between FoF and physical frailty were found. The first model demonstrated that physically frail older adults had a higher adjusted risk of FoF compared to less physically frail individuals [odds ratio $(\mathrm{OR})=11.91 ; 95 \%$ confidence interval $(\mathrm{Cl})$ : 7.1719.78]. In the second model, high FoF was discovered in physically frail adults age $\geq 80$ (OR $=11.41 ; 95 \% \mathrm{Cl}: 6.50-20.04)$ and women $(\mathrm{OR}=1.97 ; 95 \% \mathrm{Cl}: 1.08-3.59)$. In the final adjusted model, physically frail older adults had a higher FoF compared to less physically frail adults $(\mathrm{OR}=10.02 ; 95 \% \mathrm{Cl}: 4.24-23.70)$, and higher education lowered the FoF score (OR $=0.57 ; 95 \% \mathrm{Cl}: 0.34-0.96 ; p=0.034)$. Conclusions. The multivariate analysis demonstrated that being physically frail was the main risk factor for high FoF, followed by the female gender.

Key words: cognitive dysfunction, aged, frailty.

Kurková P, Kisvetrová H, Horváthová M, Tomanová J, Bretšnajdrová M, Herzig R. Fear of falling and physical performance among older Czech adults. Fam Med Prim Care Rev 2020; 22(1): 32-35, doi: https://doi.org/10.5114/fmpcr.2020.92503.

\section{Background}

The development of medical technologies in the last century has led to a substantial extension of human life, especially in terminally ill and frail older adults with chronic, life-threatening diseases [1]. Frailty can be understood as a multifactorial, multifaceted, dynamic and syndromic condition resulting from the given arrangement between biopsychosocial and environmental factors [2].

One approach considers frailty to be a decline in physical functioning. There are a plethora of the assessment tools for evaluating of the physical performance and/or physical frailty in older adults. The physical frailty phenotype, as described by Fried et al. [3], is based on five predefined physical frailty criteria, which are well known and most frequently used by researchers [4]. The Short Physical Performance Battery (SPPB), developed by Guralnik et al. [5], is also a widely-used scale for exploring the reduction of physical performance among older adults. Lower physical performance is associated with adverse health-related effects, such as mortality, disability in basic activities of daily living and mobility, hospitalisation, institutionalisation and falls [6, 7]. Older adults, including persons with cognitive impairment, may be unable to recognise their worsening physical function and the risk of falling. As a result, they are less attentive to the fear of falling (FoF) [8]. FoF has been defined as a constant concern about falling, which causes an individual to avoid activities that he/she is otherwise capable of performing, and a loss of self-efficacy to perform some activities without falling [9]. FoF has been associated with potentially serious outcomes, such as reductions in activities of daily living or social activities, reduction in the ability to perform physical activity, worsening of quality of life and an increase in future falls [2, 10-11].

The most frequent scale for testing FoF is the Falls Efficacy Scale-International (FES-I) [12], which was developed and validated in older adults across cultures and in persons with and without cognitive impairment [13-15]. However, only a few studies have focused on physical frailty and the associated factors among older adults with/without cognitive impairment [8, 16] or FES-I characteristics in samples of people with specific chronic conditions [17].

\section{Objectives}

Considering previous research findings, the objective of this study was to analyse the factors associated with FoF in a sample of older Czech adults in a community-dwelling environment. 


\section{Material and methods}

\section{Study sample}

Participants meeting the following criteria were included: (1) aged 65 years or more; (2) Mini-Mental State Examination (MMSE) score in a range between 20-30 [18]; (3) consenting to be included in the survey. The exclusion criteria for all participants were as follows: inability to walk $10 \mathrm{~m}$ without using a walking aid and severe hearing or visual limitations preventing response to the questionnaire. The sample comprised 349 community-dwelling older adults [263 (75.4\%) female; mean age $79.5 \pm 7.0$ years]. Out of these, 140 older adults were diagnosed with early-stage dementia [101 (72.1\%) female; mean age $83.3 \pm 7.1$ years] (Table 1 ).

\section{Data collection}

Older adults were recruited from the seniors centres and from neurologic/geriatric outpatient departments of university hospitals in Hradec Králové, Olomouc and Ostrava in the Czech Republic, where physicians diagnosed dementia. First, a research nurse assessed their cognition (MMSE) and performed a basic examination of eyesight and hearing before enrolling them in the study. A research nurse and a student, trained in administering the FES-I questionnaire used in the study [12], provided them with the questionnaires and explained how to complete them. The included respondents also underwent an assessment of their physical performance using the SPPB [5]. A Czech version of the FES-I questionnaire and the SPPB was used in the study [19-20]. Socio-demographic information was collected during a standardised interview.

The study was carried out between 2017 and 2018 and involved a longitudinal survey of the trajectory of quality of life among older adults with early-stage dementia in the Czech Republic (registered at Clinical Trials.gov, No. NCT02845830).

\section{Measures}

The FES-I was created to assess the level of FoF while performing activities of daily living. It consisted of 16 items based on the FES (10 original items assessing basic activities and 6 additional items assessing more demanding physical and social activities). It included items ranked between 1 and $4: 1$ being the absence of concern, and 4 the greatest concern. The scoring range of the complete scale was between 16 (no concern at all) and 64 (the greatest concern). The total score ranged from 16 to 64, where higher scores indicated more concern about falling [12].

SPPB was used to measure physical performance. This was a composite measure assessing walking speed, standing balance and sit-to-stand performance. Each SPPB component test (balance and gait) was ranked 0 (did not attempt or could not do the test) to 4 (the highest category of performance) [5].

\section{Ethics}

The Ethics Committee of the Faculty of Health Sciences, Palacký University Olomouc, Czech Republic (No. UPOL85361/1040-2015), approved the study. All subjects signed an informed consent form before enrolment.

\section{Data analysis}

The IBM SPSS Statistics (Version 23.0; IBM, NY, USA) program was used for data processing. The data was described using absolute and relative frequencies, including the mean and standard deviation (SD). Univariate statistics were performed using the Fisher exact test. Multivariate statistical processing was carried out using logical regression. All tests were performed at a level of $p=0.05$.

\section{Results}

Table 1 shows the baseline characteristics of the global sample, categorised by FoF status. There was no difference between men and women in the FES-I assessment. Older and physically frailer adults had higher FES-I values. Older adults with dementia also had higher FES-I values. The FES-I scores correlated with education, as older adults with higher education had lower FES-I scores.

\begin{tabular}{|c|c|c|c|c|c|c|c|}
\hline & \multicolumn{2}{|c|}{ FES-I Low $(n=71)$} & \multicolumn{2}{|c|}{ FES-I Medium ( $n=122)$} & \multicolumn{2}{|c|}{ FES-I High $(n=156)$} & \multirow[t]{2}{*}{$p$} \\
\hline & $n$ & $\%$ & $n$ & $\%$ & $n$ & $\%$ & \\
\hline $\begin{array}{l}\text { Gender } \\
\text { male } \\
\text { female }\end{array}$ & $\begin{array}{l}21 \\
50\end{array}$ & $\begin{array}{l}29.6 \\
70.4\end{array}$ & $\begin{array}{l}31 \\
91\end{array}$ & $\begin{array}{l}25.4 \\
21.4\end{array}$ & \begin{tabular}{|l}
34 \\
122
\end{tabular} & $\begin{array}{l}21.8 \\
78.2\end{array}$ & 0.439 \\
\hline $\begin{array}{l}\text { Age } \geq 80 \\
\text { yes } \\
\text { no }\end{array}$ & $\begin{array}{l}18 \\
53\end{array}$ & $\begin{array}{l}25.4 \\
74.6 \\
\end{array}$ & $\begin{array}{l}46 \\
76 \\
\end{array}$ & $\begin{array}{l}37.7 \\
62.3 \\
\end{array}$ & $\begin{array}{l}96 \\
60 \\
\end{array}$ & $\begin{array}{l}61.5 \\
38.5\end{array}$ & $<0.000^{\mathrm{a}}$ \\
\hline $\begin{array}{l}\text { Age } \\
\quad \text { mean (SD) }\end{array}$ & \multicolumn{2}{|c|}{$75.1(6.1)$} & \multicolumn{2}{|c|}{$77.0(6.7)$} & \multicolumn{2}{|c|}{$81.6(8.4)$} & $<0.0001^{b}$ \\
\hline $\begin{array}{l}\text { SPPB } \\
\text { grade } 3 \\
\text { grade } 1 \text { and } 2\end{array}$ & $\begin{array}{l}18 \\
53\end{array}$ & \begin{tabular}{|l|}
25.4 \\
74.6
\end{tabular} & $\begin{array}{l}28 \\
94\end{array}$ & $\begin{array}{l}23.0 \\
77.0\end{array}$ & $\begin{array}{l}123 \\
33\end{array}$ & $\begin{array}{l}78.8 \\
21.2\end{array}$ & $<0.0001^{a}$ \\
\hline $\begin{array}{l}\text { MMSE } \\
\text { patients with dg. dementia }(\leq 25) \\
\text { patients without dementia }(\geq 26)\end{array}$ & $\begin{array}{l}14 \\
57\end{array}$ & $\begin{array}{l}19.7 \\
80.3\end{array}$ & $\begin{array}{l}24 \\
98 \\
\end{array}$ & $\begin{array}{l}19.7 \\
80.3\end{array}$ & $\begin{array}{l}102 \\
54\end{array}$ & $\begin{array}{l}65.4 \\
34.6\end{array}$ & $<0.0001^{a}$ \\
\hline $\begin{array}{l}\text { MMSE } \\
\quad \text { mean (SD) }\end{array}$ & \multicolumn{2}{|c|}{$28.2(3.0)$} & \multicolumn{2}{|c|}{$27.8(3.0)$} & \multicolumn{2}{|c|}{$24.5(3.8)$} & $<0.0001^{b}$ \\
\hline $\begin{array}{l}\text { Education } \\
\text { elementary } \\
\text { vocational } \\
\text { secondary } \\
\text { tertiary }\end{array}$ & $\begin{array}{l}15 \\
13 \\
38 \\
5\end{array}$ & $\begin{array}{l}21.1 \\
18.3 \\
53.5 \\
7.0\end{array}$ & $\begin{array}{l}17 \\
31 \\
58 \\
16\end{array}$ & $\begin{array}{l}13.9 \\
25.4 \\
47.5 \\
13.1\end{array}$ & $\begin{array}{l}47 \\
50 \\
50 \\
9\end{array}$ & $\begin{array}{l}30.1 \\
32.1 \\
32.1 \\
5.8\end{array}$ & $0.0003^{a}$ \\
\hline
\end{tabular}

${ }^{a}$ Fisher's exact test; ${ }^{b}$ ANOVA; $p$ - statistical significance ( $p$-values < 0.05 are highlighted in bold); SPPB - grade 1: an overall score of $12-10$ points suggested good physical performance; grade 2: 9-7 points meant impaired physical performance ("physical pre-frailty"); grade 3: a score lower than 6 points signified the presence of physical frailty and, consequently, an increased risk of a lack of self-sufficiency [5]. 


\section{Physical frailty and fear of falling}

Table 2 presents the predictions of a high FES-I score using logistic regression. Three models were created using logical regression to predict the adjusted association between physical frailty and FoF.

The first non-adjusted Model 1 confirmed that physically frail adults (SPPB grade 3 ) had a higher risk of FoF compared to less physically frail adults (SPPB grades 1 and 2), (OR = 11.91; 95\% Cl: 7.17-19.78; $p<0.0001)$.

In the adjusted Model 2, gender and age were associated with FoF. Physically frail older adults (OR $=11.4195 \% \mathrm{Cl}: 6.50$ $-20.04 ; p<0.0001)$ and women $(\mathrm{OR}=1.97 ; 95 \% \mathrm{Cl}: 1.08-3.59$; $p=0.027)$ had a higher risk of FoF.

In the adjusted Model 3, FoF was associated only with physical frailty and education. Physically frail adults had a higher risk of FoF (OR = 10.02; 95\% Cl: 4.24-23.70; $p<0.0001$ ), and higher education lowered the risk of FoF $(\mathrm{OR}=0.57 ; 95 \% \mathrm{Cl}: 0.34$ $-0.96 ; p=0.034)$.

\begin{tabular}{|c|c|c|}
\hline & \multicolumn{2}{|l|}{ High FES-I } \\
\hline & OR $(95 \% \mathrm{Cl})$ & $p$ \\
\hline $\begin{array}{l}\text { Model } 1 \\
\text { physical frailty }\end{array}$ & 11.91 (7.17-19.78) & $<0.0001$ \\
\hline $\begin{array}{l}\text { Model } 2 \\
\text { physical frailty } \\
\text { age } \geq 80 \\
\text { female gender }\end{array}$ & $\begin{array}{l}11.41(6.50-20.04) \\
1.360(0.783-2.362) \\
1.97(1.08-3.59)\end{array}$ & $\begin{array}{l}<0.0001 \\
0.275 \\
\mathbf{0 . 0 2 7}\end{array}$ \\
\hline $\begin{array}{l}\text { Model } 3 \\
\text { physical frailty } \\
\text { age } \geq 80 \\
\text { female gender } \\
\text { education } \\
\text { MMSE } \leq 25\end{array}$ & $\begin{array}{l}10.02(4.24-23.70) \\
1.34(0.764-2.348) \\
1.82(0.99-3.33) \\
0.57(0.34-0.96) \\
1.057(0.45-2.49)\end{array}$ & $\begin{array}{l}<0.0001 \\
0.308 \\
0.052 \\
\mathbf{0 . 0 3 4} \\
0.899\end{array}$ \\
\hline
\end{tabular}

Logistic regression models between physical frailty and fear of falling Model 1 non-adjusted; Model 2 adjusted for age and gender; Model 3 adjusted for age, gender, education and MMSE; $p$ - statistical significance ( $p<0.05$ highlighted in bold).

\section{Discussion}

The findings from descriptive statistics showed a significant association between dementia and higher FoF. Older and physically frailer adults also had higher FoF scores. The findings of this study were in accordance with those of other studies [2, 21], where correlations between the variables in question were confirmed. In the present study, FoF also correlated with education, as older adults with higher education showed lower FoF scores.

In this study, all three models showed associations between physical frailty and FoF. In a study by Moreira et al. [17] on 855 older adults $(73.0 \pm 5.9$ years; $67.1 \%$ female), physical frailty assessed with Fried et al.'s scale was the risk factor with the greatest strength of associations with FoF in both non-diabetic and diabetic older adults $(\mathrm{OR}=1.79 ; 95 \% \mathrm{Cl}: 1.18-2.71$ and $\mathrm{OR}=2.31 ; 95 \% \mathrm{Cl}: 1.14-4.67)$. In a representative cohort study of 3,257 Chinese people aged more than 55 years (70.1 \pm 9.0 years, $51.1 \%$ female) [22], a frailty index constructed using 33 health deficits, but excluding falls and fractures, was also associated with an increased risk of recurrent falls $(O R=1.54 ; 95 \% \mathrm{Cl}$ : 1.34-1.76), suggesting that physical frailty played an important role in the progression of FoF [17]. Therefore, the findings of this study indicated that physical frailty was the most determinant factor for FoF among community-dwelling older adults. However, the cross-sectional design of this study did not allow for the research of any conclusion on the causal association.
In the non-adjusted Model 1, the associations between physical frailty and FoF were tested. Physically frail adults (SPPB grade 3) had a higher adjusted risk of FoF compared to less physically frail adults. Contrary to the findings of the present study, a population-based study on 906 community-dwelling older Turkish adults (71.5 \pm 5.6 years; $50.6 \%$ female) indicated that physical frailty assessed with Fried et al.'s scale was not associated with FoF in the multivariate model [23].

In the adjusted Model 2, adjusted for physical frailty, age and female gender, physical frailty and female gender were associated with FoF. Similar results were obtained in a crosssectional study (183 older adults; mean age 78.4 years; $80.3 \%$ female) [2], where FoF was associated with physical frailty for the female gender $(\mathrm{OR}=3.48 ; 95 \% \mathrm{Cl}: 1.31-9.13)$. In this study, physical frailty was assessed with Fried's phenotype criteria. Other studies reported that older women were more likely to have FoF, because they fell more often than men, and this experience could increase their FoF [17, 24]. In the study by Moreira et al. [17], female gender was the only factor that remained independently associated with FoF in the final models of binary logistic regression. Female gender was the second risk factor with a higher strength of association with FoF in both non-diabetic and diabetic older adults (OR $=1.69 ; 95 \% \mathrm{Cl}$ : 1.36-2.11 and $\mathrm{OR}=1.93 ; 95 \% \mathrm{Cl}: 1.36-2.75)$. This association between female gender and FoF was also confirmed in 9,033 older Korean adults (OR $=1.64 ; 95 \% \mathrm{Cl}: 1.447-1.858)$ [24].

In the adjusted Model 3, FoF was associated only with physical frailty and education. Physically frail older adults had a higher adjusted risk of FoF, and higher education lowered the risk of FoF. The association between female gender and FoF was close to the statistical significance. The findings of the present study were consistent with previous studies conducted on older populations in general $[17,25]$. In contrast, a Thai study with 386 community-dwelling older adults $(71.11 \pm 7.73$ years, $64.5 \%$ female) showed that more than $50 \%$ of adults were illiterate and had a relatively lower education level [25]. A Korean study showed an association between education and FoF $(O R=1.18$; $95 \%$ Cl: 1.031-1.344) [24]. In addition, in a study by Shirooka et al. on 483 community-dwelling older adults (73.3 \pm 5.1 years, $68.3 \%$ female) [8], a stepwise multivariate logistic regression analysis showed that the score on the attention and calculation subsection of the MMSE was positively associated with the presence of FoF in physically frail older adults $(\mathrm{OR}=1.83 ; 95 \%$ $\mathrm{Cl}$ : 1.08-3.12). However, this result was not confirmed in the present study. On the contrary, in the study by Shirooka et al. [8], cognitive impairment was not associated with FoF in physically non-frail older adults.

\section{Limitations of the study}

The main limitation of this study was the cross-sectional design. Furthermore, causality could not be demonstrated in the association between physical frailty and FoF in this study. Moreover, the results on associations between physical frailty and FoF might have been influenced by factors not investigated in the study, e.g. missing information on fall history, physical activity or comorbidities. Other limitations are the multiple measurements used to identify physical frailty among older adults. In our study, physical frailty was defined by using the SPPB, where a score lower than 6 points signified the presence of physical frailty and, consequently, an increased risk of a lack of self-sufficiency. Further studies are needed to confirm this association between physical frailty and FoF and the importance of other variables affecting this association.

\section{Conclusions}

The present study confirmed differences in the factors associated with FoF among community-dwelling older adults with and without dementia. Multivariate analysis also demonstrated that being physically frail was the main risk factor for FoF, followed by other factors, including female gender. 
Source of funding: This study was supported by the Ministry of Health of the Czech Republic, grant No.16-28628A.

Conflicts of interest: The authors declare no conflicts of interest.

\section{References}

1. Kisvetrova $\mathrm{H}$, Joanovic $\mathrm{E}$, Vevoda J, et al. Dying care nursing intervention in the institutional care of end-of-life patients. Int J Nurs Knowl 2017; 28: 131-137.

2. Esbrí-Víctor M, Huedo-Rodenas I, López-Utiel M, et al. Frailty and fear of falling: the FISTAC Study. J Frailty Aging 2017; 6: 136-140, doi: 10.14283/jfa.2017.19.

3. Fried LP, Tangen CM, Walston J, et al. Frailty in older adults: evidence for a phenotype. J Gerontol A Biol Sci Med Sci 2001; 56: M146$-\mathrm{M} 156$.

4. Verlaan S, Ligthart-Melis GC, Wijers SLJ, et al. High prevalence of physical frailty among community-dwelling malnourished older adults - a systematic review and meta-analysis. J Am Med Dir Assoc 2017; 18(5): 374-382, doi: 10.1016/j.jamda.2016.12.074.

5. Guralnik JM, Ferrucci L, Simonsick EM, et al. Lower extremity function in persons over the age of 70 years as a predictor of subsequent disability. N Engl J Med 1995; 332: 556-561.

6. Romero Rizos L, Abizanda Soler P. Frailty as a predictor of adverse events in epidemiological studies: literature review. Rev Esp Geriatr Gerontol 2013; 48: 285-289.

7. Muszalik M, Borowiak E, Kotarba A, et al. Adaptation and reliability testing of the SHARE-FI instrument for the assessment of risk of frailty syndrome among older Polish patients. Fam Med Prim Care Rev 2018; 20(1): 36-40, doi: 10.5114/fmpcr.2018.73702.

8. Shirooka H, Nishiguchi S, Fukutani N, et al. Cognitive impairment is associated with the absence of fear of falling in community-dwelling frail older adults. Geriatr Gerontol Int 2017; 17(2): 232-238, doi: 10.1111/ggi.12702.

9. Tinetti ME, Powell L. Fear of falling and low self-efficacy: a case of dependence in elderly persons. J Gerontology 1993; 48: 35-38.

10. Malini FM, Lourenco RA, Lopes CS. Prevalence of fear of falling in older adults, and its associations with clinical, functional and psychosocial factors: the Frailty in Brazilian Older People-Rio de Janeiro Study. Geriatr Gerontol Int 2016; 3: 336, doi: 10.1111/ggi.12477.

11. Kupcewicz E, Wróblewska T, Kędzia A, et al. Evaluation of life satisfaction and functional fitness of people over 60 years of age living in a nursing home and home environment. Fam Med Prim Care Rev 2016; 18(4): 437-442, doi: 10.5114/fmpcr.2016.63698.

12. Yardley L, Beyer N, Hauer K. Development and initial validation of the Falls Efficacy Scale International (FES-I). Age Ageing 2005; 34: 614-619.

13. Figueiredo D, Santos S. Cross-cultural validation of the Falls Efficacy Scale-International (FES-I) in Portuguese community-dwelling older adults. Arch Gerontol Geriatr 2017; 68: 168-173.

14. Kovács É, Rozs F, Petridisz A, et al. Cross-cultural validation of the Falls Efficacy Scale-International to assess concerns about falls among Hungarian community-living older people. Disabil Rehabil 2017; 17: 1-6.

15. Kisvetrová H, Skoloudik D, Herzig R, et al. Psychometric Properties of the Czech Version FES-I in patients with early-stage dementia. Dement Geriatr Cogn Dis Extra 2019; 9: 319-329, doi: 10.1159/000501676.

16. Hauer KA, Kempen GI, Schwenk M, et al. Validity and sensitivity to change of the falls efficacy scales international to assess fear of falling in older adults with and without cognitive impairment. Gerontology 2011; 57: 462-472.

17. Moreira BS, Sampaio RF, Diz JBM, et al. Factors associated with fear of falling in community-dwelling older adults with and without diabetes mellitus: Findings from the Frailty in Brazilian Older People Study (FIBRA-BR). Exp Geront 2017; 89: 103-111, doi: 10.1016/j. exger.2017.01.004.

18. Folstein M, Folsten S, McHugh P. Mini-mental state: a practical method for grading the cognitive state of patients for the clinician. J Psychiatry Res 1975; 12: 189-198.

19. Reguli Z, Svobodová L. Česká verze diagnostiky strachu z pádů u seniorů - FES-I (Falls Efficacy Scale International). Studia Sportiva 2011; 5: 5-12, doi: 10.5817/StS2011-2-1 (in Czech).

20. Berková $\mathrm{M}$, Topinková $\mathrm{E}$, Mádlová $\mathrm{P}$, et al. „Krátká baterie pro testování fyzické zdatnosti seniorů“ - pilotní studie a validizace testu u starších osob v České republice. Vnitřni Lékařství 2013; 59: 256-263 (in Czech).

21. Morley JE. Frailty, falls, and fractures. J Am Med Direct Assoc 2013; 14: 149-151.

22. Fang $X$, Shi J, Song $X$, et al. Frailty in relation to the risk of falls, fractures, and mortality in older Chinese adults: results from the Beijing longitudinal study of aging. J Nutr Health Aging 2012; 16: 903-907.

23. Akin S, Mazicioglu MM, Mucuk S, et al. The prevalence of frailty and related factors in community-dwelling Turkish elderly according to modified Fried frailty index and FRAIL scales. Aging Clin Exp Res 2015; 27: 703-709.

24. Kim A, So WY. Prevalence and correlates of fear of falling in Korean community-dwelling elderly subjects. Exp Geront 2013; 48: 1323-1328 .

25. Thiamwong L, Suwanno J. Fear of falling and related factors in a community-based study of people 60 years and older in Thailand. Int J Gerontol 2017; 11: 80-84, doi: 10.1016/j.ijge.2016.06.003.

Tables: 2

Figures: 0

References: 25

Received: 19.07.2019

Reviewed: 23.07.2019

Accepted: 15.09.2019

Address for correspondence:

Petra Kurková, PhD

Katedra antropologie a zdravovědy

Pedagogická fakulta

Univerzita Palackého v Olomouci

Žižkovo nám. 5

77140 Olomouc

Czech Republic

Tel.: +420585635506

E-mail: petra.kurkova@upol.cz 